\section{NAPCRG CONGRATULATES AAFP NATIONAL RESEARCH NETWORK ON ITS 10TH ANNIVERSARY}

The North American Primary Care Research Group congratulates the American Academy of Family Physicians National Research Network (AAFP NRN) in celebrating its 10-year anniversary in November 2009. The AAFP NRN has received generous support from the AAFP since its inception and provides varied research and quality improvement opportunities for family physicians and other primary care clinicians contributing to the generation of new knowledge and lifelong learning. The AAFP NRN mission is to support, conduct and disseminate practice-based primary care research that improves healthcare and benefits the health of patients, their families and communities. Among its substantive areas of interest are patient safety, practice change, patient-centered care, patient behavioral and lifestyle changes, and primary/secondary prevention. Having completed 20 studies and published 32 peer-reviewed articles, its research methods include surveys, observational studies, randomized clinical trails at the patient and practice levels, and comparative effectiveness studies.

Wilson Pace MD, FAAFP, has served as the NRN Director since 2004. Dr Pace is a practicing family physician and researcher. A faculty member at the University of Colorado and a leader of practice-based research networks since 1998, he brings an academic voice and resources to NRN.

The AAFP NRN has launched a new Residency Branch supporting residency programs in their efforts to engage residents in practice-based research. The Residency Branch's goal is to develop a curriculum for residents and faculty and to ultimately provide residents with an education about practice-based research before they graduate and begin practice. NRN will also provide a system to support the development of study concepts and logistical support to design and complete the studies.

With a membership of over 2,500 clinicians, the AAFP NRN has formal linkages with 11 local and regional practice-based research networks (PBRNs) and actively engages regional networks in all major projects. It has actively expanded its research collaborations to other professional societies as well as the
Robert Graham Center, the Institute for Healthcare Improvement and multiple academic centers. Much of its funding has come from the US Department of Health and Human Services, Agency for Healthcare Research and Quality (AHRQ).

The AAFP NRN is proud to be the primary network home for a newly established network of electronic health record practices called DARTNet that will eventually expand to include numerous regional networks and academic centers. Touted as one of AHRQ's most significant undertakings, DARTNet will facilitate the standardization of patient care data for practice improvement and enhancing research activities.

A study it is currently involved in is a randomized clinical trial of behavioral change called Americans in Motion-Healthy Intervention (AIM-HI) involving 24 practices in 3 PBRNs across the United States. AIM-HI studies the effects of counseling and physical fitness on patients' physical and emotional health through the collection of blood samples and other quantitative data.

The AAFP NRN has recently begun the development of a network focusing on evaluating and improving collaborative care between co-located primary care and mental health providers. These efforts would not be possible without the ongoing support of the AAFP, family physician researchers, and study coordinators across the country and practicing family physicians, general internists, general pediatricians, nurse practitioners, physician assistants and hundreds of office staff members

NAPCRG appreciates the AAFP's continued support of primary care research through its National Research Network and the leadership it provides to the primary care research community.

Thanks to James M. Galliher, PhD, for contributing historical nformation.

Allen Dietrich, MD, President, NAPCRG

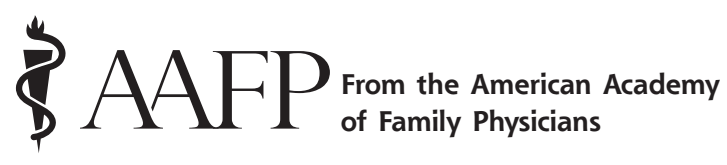

Ann Fam Med 2009;7:378-379. doi:10.1370/afm.1029.

\section{ACADEMY LAUNCHES COMPREHENSIVE PATIENT-CENTERED MEDICAL HOME RESOURCES}

In early June, the Academy launched a new area on its Web site. The patient-centered medical home, or PCMH, section of the Web site, was created by the 